\title{
Progressive supranuclear palsy-pure akinesia with gait freezing syndrome
}

INSERM

\section{Source}

INSERM. (1999). Orphanet: an online rare disease and orphan drug data base.

Progressive supranuclear palsy-pure akinesia with gait freezing syndrome.

ORPHA:240094

PSP-Pure akinesia with gait freezing (PSP-PAGF) is an atypical variant of progressive supranuclear palsy (PSP; see this term), a rare late-onset neurodegenerative disease. 